\title{
25 Research Square \\ Does General Comorbidity Impact the Postoperative Outcomes After Surgery for Large and Giant Petroclival Meningiomas?
}

Alexandre Roux ( $\square$ alexandre.roux@neurochirurgie.fr)

GHU Paris: Groupe Hospitalier Universitaire Paris psychiatrie \&amp; neurosciences https://orcid.org/0000-0002-9597-673X

\section{Lucas Troude}

CHU Nord

\section{Guillaume Baucher}

CHU Nord

Florian Bernard

CHU Angers

Johan Pallud

GHU Paris: Groupe Hospitalier Universitaire Paris psychiatrie \&amp; neurosciences

Pierre-Hugues Roche

$\mathrm{CHU}$ Nord

\section{Research Article}

Keywords: Petroclival meningioma, Morbidity, Risk factors, General condition, Surgery

Posted Date: March 15th, 2021

DOl: https://doi.org/10.21203/rs.3.rs-285054/v1

License: (c) (i) This work is licensed under a Creative Commons Attribution 4.0 International License.

Read Full License

Version of Record: A version of this preprint was published at Neurosurgical Review on June 12th, 2021. See the published version at https://doi.org/10.1007/s10143-021-01580-8. 


\section{Abstract}

Objective

We assessed the role of the general condition of the patient in addition to usual anatomical reasoning to improve the prediction of personalized surgical risk for patients harbouring a large and giant petroclival meningiomas.

Methods

Single-center, retrospective observational study including adult patients surgically treated for a large and giant petroclival meningioma between January 2002 and October 2019 in a French tertiary neurosurgical skull-base center by one Neurosurgeon. Inclusion criteria were: 1) histopathologically proven meningioma; 2) larger than $3 \mathrm{~cm}$ in diameter; 2) located within the upper two-thirds of the clivus, the inferior petrosal sinus, or the petrous apex around the trigeminal incisura, medial to the trigeminal nerve. Clinical and radiological characteristics were gathered preoperatively including ASA score, the modified Frailty Index and the Charlson Comorbidity Index. Post-operative severe neurological and nonneurological complications were collected.

Results

A total of 102 patients harbouring a large and giant petroclival meningioma were included. The rate of postoperative death was $3.0 \%$ related to a congestive heart failure $(n=1)$, a surgical site hematoma $(n=1)$, and an ischemic stroke $(n=1)$. A severe neurological impairment was found in $12.8 \%$ and a severe nonneurological morbidity was found in $4.0 \%$. The overall rate of severe morbidity and mortality was $15.7 \%$ after large and giant petroclival meningioma surgery. The presence of brainstem peri-tumoral edema (adjusted OR, 4.83 [95\% $\mathrm{Cl} 1.84-7.52], \mathrm{p}=0.028$ ) was independently associated with a history of postoperative severe neurological morbidity. Male gender (adjusted OR, 7.42 [95\% Cl 1.05-49.77], $\mathrm{p}=0.044$ ), major cardiovascular morbidity (adjusted $\mathrm{OR}, 9.5$ [95\% $\mathrm{Cl} 1.05-86.72], \mathrm{p}=0.045$ ), and an ASA score $\geq 2$ (adjusted OR, 11.09 [95\% $\mathrm{Cl} 1.46-92.98$ ], $\mathrm{p}=0.038$ ) were independently associated with a history of postoperative severe non-neurological morbidity. A modified Frailty index $\geq 1$ (adjusted OR, 3.13 [95\% Cl 1.07-9.93], $\mathrm{p}=0.047$ ), and a low neurosurgical experience (adjusted OR, 5.38 [95\% Cl 1.3820.97], $p=0.007$ ) were independently associated with a history of postoperative overall morbidity and mortality.

Conclusions

This study suggests to add scores assessing the patient general condition in daily practice to improve the selection of patients eligible for surgery. Collaborative international multicenter studies will be necessary to confirm these results and allow their implementation in clinical routine.

\section{Introduction}


Petroclival meningiomas (PCMs) are rare and enduring tumour requiring one or more complex surgical resection[28]. Large and giant PCMs are defined as the main tumour diameter larger than $2.5 \mathrm{~cm}$ and originate from the upper two-thirds of the clivus, the petrous apex around the trigeminal notch or the inferior petrosal sinus or, medial or around to the trigeminal incisura[38]. Surgical removal of a PCM has a high morbidity and mortality profile, related to: 1) the deep seated location, which requires complex skull base approaches[32]; 2) the induration and the adherences of meningiomas, which potentially make their intraoperative manipulation difficult; 3 ) the propensity to engulf nerves and blood vessels, to invade the cavernous sinus and to extend to cranial fossae foramina; and 4) the large tumour volume at time of surgery. In reported series, mortality ranged $0-10 \%$, the incidence of cranial nerves deficits ranged 29$76 \%$, and major complications ranged $8-45 \%[2,5,7,11,23,26,28,31,34,40]$. In order to predict the risk of the PCM surgery, Adachi et al. in 2009, developed a dedicated scoring system, i.e. the ABC Surgical Risk Score, based upon pure anatomical criteria[1]. However, ABC Surgical Risk Score score did not encompass the general condition of the patient and, especially, comorbidities. Other scores assessing patients' comorbidities have been developed and are widely used, as the American Society of Anaesthesiologists (ASA) score[33], the modified Frailty Index[25], and the Charlson Comorbidity Index[9]. Unfortunately, neurosurgical and co-morbid predictors are rarely associated in the assessment of perioperative risk factors. To date, no study assessed the impact of scores assessing patient comorbidities for large and giant PCMs. However, the neurosurgeon intuitively assesses the surgical risk by taking into account anatomical data, as suggested by Adachi et al.[1], but also by taking into account the patient's comorbidities. Indeed, it is common to maintain a close clinico-radiological monitoring for a large and giant PCM in an elderly patient with numerous comorbidities.

Here, we suggested that integrating scores assessing patient comorbidities together with the usual anatomical reasoning could improve the prediction of personalized surgical risk for patients harboring a subtotal resection for a large and giant PCM.

\section{Material And Methods}

\section{Data source}

We performed a single-center, retrospective cohort study of adult patients ( $\geq 18$ year-old) with a subtotal resection, which is our attitude, for large and giant PCM between January 2002 and October 2019 in a French tertiary neurosurgical skull-base center by the same senior neurosurgeon (PHR). Inclusion criteria were: 1) histopathologically proven meningioma; 2) larger diameter $\geq 3 \mathrm{~cm}$; 2) location within the upper two-thirds of the clivus, the inferior petrosal sinus, or the petrous apex around the trigeminal incisura, medial to the trigeminal nerve. We used the Strengthening the Reporting of Observational Studies in Epidemiology (STROBE) Statement, as recommended[14].

\section{Data collection}

Data were obtained from the medical records using a protocol designed for the study. 
Clinical characteristics were: sex, age, past medical history, the ASA physical status classification system score, the modified Frailty index, and the Charlson comorbidity index (Fig. 1). All patients underwent extensive pre- and post-operative neurological examinations with detailed medical history (including major diseases such as thromboembolism, respiratory, neoplastic, and other neurologic illness), the presence of a major cardiovascular morbidity (heart failure, rhythmic heart disease and coronary artery disease), functional independence using the Karnofsky Performance Status (KPS) score, and detailed cranial nerve $(\mathrm{CN})$ testing. Swallowing and auditory function were assessed by an Otolaryngologist.

Meningioma imaging characteristics, systematically gathered from preoperative MRI, were : side, main insertion, secondary extension, largest diameter, volume, peri-tumoral edema, bone involvement, hydrocephalus, and mass effect on brainstem.

Surgical characteristics were : period of inclusion (the first half cases versus the second half cases) and surgical approach (anterior petrosectomy versus combined approaches).

Postoperative characteristics were: histopathological report, day 1 post-operative neurological examination, post-operative complications within the first month. Severe neurological impairment was defined as the presence of a postoperative: 1) surgical site hematoma requiring a new surgical procedure; 2) stroke; 3) refractory epileptic seizures; 4) long tracts deficits without stroke and/or 5) IX-X-XI palsy. Severe non-neurological morbidity was defined as postoperative: 1) congestive heart failure; 2) lung infection and; 3) pulmonary embolism.

\section{Statistical analysis}

To determine factors associated with a history of postoperative complications, univariate analyses were performed, computing unadjusted Odds Ratios (OR) and using the Chi square or Fisher's exact tests for comparing categorical variables, and the unpaired t-test or Mann-Whitney rank-sum test for continuous variables, as appropriate. Variables associated at the $p<0.200$ level in unadjusted analysis were then entered into backward stepwise logistic regression models.

We performed a backward stepwise selection of variables, in a subgroup of 73 patients according to available imaging data, removing the least significant variables one after the other, and defining the least significant variable as having the highest $p$-value in the model.

The final model retained only the variables significant at the $\mathrm{P}<0.05$ level. Statistical analyses were performed using JMP software (version 14.3.0, SAS Institute Inc, Cary, USA).

\section{Standard protocol approvals, registrations, and patient consents}

Informed consent was obtained from all patients. This study received required authorizations (IRB\#1: 2019/20) of the French College of Neurosurgery (IRB00011687).

\section{Results}




\section{Clinical, imaging, histopathological, and treatment-related characteristics}

Patients' clinical characteristics are detailed in Table 1. A total of 102 patients (82 women, mean age $53.4+/-10.9)$ harboring a large and giant PCM were included. Ten patients $(9.8 \%)$ underwent a previous surgical resection in another center and four of them (3.9\%) had a postoperative radiotherapy. Two patients $(2.0 \%)$ had a previous radiotherapy without surgery in another center. The median ASA score was 2 (range $1-3$ ) with $45.1 \%$ of patients with a ASA score at 2 (mild systemic disease). The median modified Frailty Index and Charlson comorbidity index were 0 in $58.8 \%$ and $67.8 \%$ of patients with no significant disease, respectively. 
Table 1

Main clinical characteristics of the study sample $(n=102)$

\begin{tabular}{|c|c|c|}
\hline Parameters & $\mathbf{n}$ & $\%$ \\
\hline \multicolumn{3}{|l|}{ Clinical characteristics } \\
\hline Sex & 20 & 19.6 \\
\hline Male & 82 & 80.4 \\
\hline \multicolumn{3}{|l|}{ Female } \\
\hline Age, years (mean, SD) $53.4 \pm 10.9$ & 53 & 52.0 \\
\hline$<55$ & 49 & 48.0 \\
\hline \multicolumn{3}{|l|}{$\geq 55$} \\
\hline Karnofsky Performance Status & 98 & 96.1 \\
\hline$\geq 70$ & 3 & 2.9 \\
\hline \multicolumn{3}{|l|}{$<70$} \\
\hline Cardiovascular comorbidities & 6 & 5.9 \\
\hline Yes & 96 & 94.1 \\
\hline \multicolumn{3}{|l|}{ No } \\
\hline Previous surgical resection & 10 & 9.8 \\
\hline Yes & 92 & 90.2 \\
\hline \multicolumn{3}{|l|}{ No } \\
\hline Previous radiotherapy & 6 & 5.9 \\
\hline Yes & 96 & 94.1 \\
\hline \multicolumn{3}{|l|}{ No } \\
\hline ASA Score (mean, SD) $1.8 \pm 0.7$ & 36 & 35.3 \\
\hline 1 & 46 & 45.1 \\
\hline 2 & 20 & 19.6 \\
\hline 3 & 0 & 0 \\
\hline$\geq 4$ & & \\
\hline
\end{tabular}




\begin{tabular}{|lll|}
\hline Parameters & $\mathbf{n}$ & $\%$ \\
\hline Modified Frailty Index (mean, SD) $0.6 \pm 0.8$ & 60 & 58.8 \\
0 & 32 & 31.4 \\
2 & 5 & 4.9 \\
3 & 4 & 3.9 \\
$\geq 4$ & 1 & 1.0 \\
\hline Modified Charlson comorbidity Index (mean, SD) $0.6 \pm 1.0$ & 69 & 67.6 \\
0 & 16 & 15.7 \\
1 & 10 & 9.8 \\
2 & 5 & 4.9 \\
3 & 2 & 2.0 \\
$\geq 4$ & & \\
\hline Pre-operative cranial nerve deficits & 78 & 76.5 \\
Yes & 24 & 23.5 \\
No & & \\
\hline Pre-operative long tract deficits & 31 & 30.4 \\
Yes & 71 & 69.6 \\
No & & \\
\hline
\end{tabular}

Patients' neurological examination are detailed in Table 2. Cranial nerves deficits were the main symptoms at diagnosis, affecting $76.5 \%$ of patients: facial hypoesthesia in $42.2 \%$, facial neuralgia in $21.6 \%$, facial paralysis in $8.8 \%$, and hearing loss in $31.4 \%$. Only $4.9 \%$ of patients had an impairment of the IX-X-XI cranial nerves and no patient had a XII impairment at diagnosis. Diplopia was present at diagnosis in $21.6 \%$ of patients: Third cranial nerve impairment in $10.8 \%$, fourth cranial nerve impairment in $4.9 \%$, and sixth cranial nerve impairment $5.9 \%$. Long tracts deficits were present in $30.4 \%$ and headaches were present in $19.6 \%$. Epileptic seizures were present in $2.9 \%$ of patients at diagnosis. 
Table 2

Preoperative neurological examination of the study sample $(n=102)$

\begin{tabular}{|lll|}
\hline Parameters & $\mathbf{n}$ & $\%$ \\
\hline Cranial nerves deficits & 78 & 76.5 \\
\hline II & 3 & 2.9 \\
\hline III & 11 & 10.8 \\
\hline V & 5 & 4.9 \\
\hline Facial neuralgia & 49 & 48.0 \\
Facial hypoesthesia & 22 & 21.6 \\
\hline VI & 43 & 42.2 \\
\hline VII & 6 & 5.9 \\
\hline VIII & 9 & 8.8 \\
\hline Hearing loss & 35 & 34.3 \\
Vestibular syndrome & 32 & 31.4 \\
\hline IX-X-XI & 11 & 10.8 \\
\hline XII & 5 & 4.9 \\
\hline Long tracts deficits & 0 & 0 \\
\hline Ataxia & 31 & 30.4 \\
\hline Proprioceptive ataxia & 36 & 35.3 \\
\hline Cerebellar ataxia & 16 & 15.7 \\
\hline Hemiparesis & 20 & 19.6 \\
\hline Other neurological manifestations & 48 & 47.1 \\
\hline Headaches & 20 & 19.6 \\
\hline Epileptic seizure & 3 & 2.9 \\
\hline Hydrocephalus & 28 & 27.5 \\
\hline
\end{tabular}

Imaging, histopathological and surgical characteristics are detailed in Table 3. Imaging characteristics were fully available for 73 patients. The median tumor volume was $21.8 \mathrm{~cm}^{3}$ (range 7.5-164.2). A mass effect on brainstem was present in all cases. A peri-tumoral edema was present in $69.9 \%$ of cases. 
Hydrocephalus was present in $38.4 \%$ of cases and hyperostosis was present in $23.3 \%$ of cases. Bone erosion was present in $4.1 \%$ of cases and a mixed erosion-condensation was present in $5.5 \%$ of cases. 
Table 3

Main imaging, surgical and histopathological characteristics of the study sample $(n=102)$

\begin{tabular}{|lll|}
\hline Parameters & $\mathbf{n}$ & $\%$ \\
\hline Imaging characteristics $(\mathbf{n}=73)$ & & \\
\hline Tumor volume (cm3) (mean, SD) 27.7 \pm 23.0 & 23 & 31.5 \\
$\geq 30$ & 50 & 68.5 \\
$<30$ & & \\
\hline Peri-tumoral edema & 51 & 69.9 \\
Yes & 22 & 30.1 \\
No & & \\
\hline Bone involvement & 3 & 4.1 \\
Erosion & 17 & 23.3 \\
Hyperostosis & 4 & 5.5 \\
Mixed & 49 & 67.1 \\
No & & \\
\hline Hydrocephalus & 28 & 38.4 \\
Yes & 45 & 61.6 \\
No & & \\
\hline Surgical characteristics $(\boldsymbol{n}=102)$ & & \\
\hline Neurosurgeon experience (number of cases) & 50 & 49.0 \\
$<50$ & 52 & 51.0 \\
$\geq 50$ & & \\
\hline Surgical approach & & \\
Transpetrosal approach & & \\
Combined approach & & \\
\hline Histopathological characteristics $(\boldsymbol{n}=102)$ & & \\
\hline
\end{tabular}

SD : Standard Deviation; WHO : World Health Organization 


\begin{tabular}{|lll|}
\hline Parameters & $\mathbf{n}$ & $\%$ \\
\hline WHO grading & 90 & 88.2 \\
Grade 1 & 11 & 10.8 \\
Grade 2 & 1 & 1.0 \\
Grade 3 & & \\
\hline SD : Standard Deviation ; WHO : World Health Organization \\
\hline
\end{tabular}

The majority of patients were treated by an isolated transpetrosal approach (73.5\%) and combined approaches were performed in $26.5 \%$ of cases. The histopathological analysis demonstrated a grade 1 , grade 2 , and grade 3 meningioma in $88.2 \%, 10.8 \%$, and $1.0 \%$ of cases respectively.

\section{Surgical outcomes}

Adverse postoperative events data are detailed in Table 4. The rate of postoperative death was $3.0 \%$ in the whole series related to a congestive heart failure $(n=1)$, a surgical site hematoma $(n=1)$, and an ischemic stroke $(n=1)$. The overall rate of severe postoperative morbidity was $15.7 \%$ : a severe neurological impairment was present in $12.8 \%$ of cases, and a severe non-neurological morbidity was present in $4.0 \%$ of cases.

Table 4

Adverse postoperative events of the study sample $(\mathrm{n}=$ 102)

\begin{tabular}{|lll|}
\hline Parameters & $\mathbf{n}$ & $\%$ \\
\hline Postoperative events & & \\
\hline Severe neurological morbidity & 13 & 12.8 \\
Ischemic Stroke & 2 & 2.0 \\
Cerebral Hematoma & 1 & 1.0 \\
Epileptic seizures & 1 & 1.0 \\
Long tracts deficits without stroke & 8 & 7.8 \\
IX-X-XI palsy & 1 & 1.0 \\
\hline Severe non-neurological morbidity & 4 & 4.0 \\
Congestive heart failure & 1 & 1.0 \\
Lung infection & 2 & 2.0 \\
Pulmonary embolism & 1 & 1.0 \\
\hline Overall severe morbidity and mortality & 16 & 15.7 \\
\hline
\end{tabular}


Table 5

Multivariate analyses $(\mathrm{n}=73)$

\begin{tabular}{|c|c|c|c|}
\hline Predictors & Adjusted Hazard Ratio & $95 \% \mathrm{Cl}$ & p-value \\
\hline \multicolumn{4}{|l|}{ Severe neurological impairment } \\
\hline Peri-tumoral edema & 4.83 & $1.84-7.52$ & 0.028 \\
\hline Yes & 1 & & \\
\hline \multicolumn{4}{|l|}{ No } \\
\hline \multicolumn{4}{|l|}{ Severe non-neurological morbidity } \\
\hline Sex & 7.42 & $1.05-49.77$ & 0.044 \\
\hline Male & 1 & & \\
\hline \multicolumn{4}{|l|}{ Female } \\
\hline Major cardiovascular morbidity & 9.5 & $1.05-86.72$ & 0.045 \\
\hline Yes & 1 & & \\
\hline \multicolumn{4}{|l|}{ No } \\
\hline ASA Score & 1 & $1.46-92.98$ & 0.038 \\
\hline$=1$ & 11.09 & & \\
\hline \multicolumn{4}{|l|}{$\geq 2$} \\
\hline \multicolumn{4}{|l|}{ Overall morbidity and mortality } \\
\hline Modified Frailty Index & 1 & $1.07-9.93$ & 0.047 \\
\hline$=0$ & 3.13 & & \\
\hline \multicolumn{4}{|l|}{$\geq 1$} \\
\hline Pre-operative long tract deficits & 1.43 & $0.45-4.61$ & 0.542 \\
\hline Yes & 1 & & \\
\hline \multicolumn{4}{|l|}{ No } \\
\hline Neurosurgeon experience (number of cases) & 5.38 & $1.38-20.97$ & 0.007 \\
\hline$<50$ & 1 & & \\
\hline$\geq 50$ & & & \\
\hline
\end{tabular}

Unadjusted of severe neurological, non-neurological and overall morbidity and mortality are detailed in Supplementary Tables 1-3. In a multivariable analysis, the presence of brainstem peri-tumoral edema (adjusted OR, 4.83 [95\% $\mathrm{Cl} 1.84-7.52$ ], $\mathrm{p}=0.028$ ) was independently associated with postoperative severe neurological morbidity. Male sex (adjusted OR, 7.42 [95\% Cl 1.05-49.77], p = 0.044), major 
cardiovascular morbidity (adjusted OR, 9.5 [95\% Cl 1.05-86.72], $\mathrm{p}=0.045$ ), and an ASA score $\geq 2$ (adjusted OR, 11.09 [95\% Cl 1.46-92.98], $p=0.038$ ) were independently associated with postoperative severe non-neurological morbidity. A modified Frailty index $\geq 1$ (adjusted OR, 3.03 [95\% Cl 1.07-9.70], $p=$ 0.040), and a low neurosurgical experience (adjusted OR, 5.17 [95\% Cl 1.32-20.18], $p=0.009$ ) were independently associated with postoperative overall morbidity and mortality.

\section{Discussion}

\section{Key results}

In this large retrospective cohort study of 102 large and giant PCM surgically treated by the same senior neurosurgeon we identified : 1) peri-tumoral edema as an independent predictor of severe neurological impairment; 2) male sex, major cardiovascular morbidity, a high ASA score as independent predictors of severe non-neurological morbidity; and 3) a high modified Frailty index and a low experience in large and giant PCM surgery as independent predictors of overall morbidity and mortality.

\section{Interpretation}

In our study, the rate of postoperative death was 3.0\% after large and giant PCM surgery with a severe neurological impairment in $12.8 \%$ and a severe non-neurological morbidity in $4.0 \%$. In reported series, mortality ranged $0-10 \%$, the incidence of cranial nerves deficits ranged $29-76 \%$, and major complications ranged $8-45 \%[2,5,7,11,23,26,28,31,34,40]$. Thereby, our overall rate of severe morbidity and mortality was $15.7 \%$ after large and giant PCM surgery in accordance with the literature[2, $4,5,7,11,17,19,23,26,28,29,31,34,40]$.

Interestingly, Adachi et al. proposed a scoring system for predicting the extent of surgical resection and the neurological outcome for skull base meningiomas[1]. In accordance with their results, we suggested that peri-tumoral edema on preoperative MRI increased the risk of postoperative severe neurological impairment, as previously described[1, $4,17,38]$. The presence of peri-tumoral edema is possibly related to the pial invasion of the brainstem[17], which may explain difficulties during tumour dissection resulting in vascular injuries and direct injury to the brainstem. However, Adachi et al. analyzed only the postoperative severe neurological impairment but not the non-neurological morbidity, which required the preoperative assessment of the patient general conditions.

Male sex was associated with a higher rate of postoperative non-neurological morbidity, which was consistent with a previous study published by Sekhar et al., where male sex was independently associated with early postoperative KPS deterioration[38]. We suggested that major cardiovascular morbidity increased the risk of postoperative non-neurological morbidity,

which remains a criterion found in all the scores assessing the patient general condition $[9,25,33]$.

The ASA scores[33] is a widely used grading system for preoperative health of the surgical patients, which was correlated, for neurosurgical procedures, with non-neurological morbidity[16, 24, 30, 35-37], 
postoperative length of stay[18] and survival[41]. The modified Frailty index[25]and the Charlson comorbidity index[9] were also studied in the neurosurgical literature with interesting results, especially concerning their highest accuracy for predicting postoperative complications compared to the ASA score[15, 22, 43]. Youngerman et al., published a large cohort of 9149 patients who underwent oncologic neurosurgery procedures with an estimation of the modified Frailty index[44]. They found that mortality, severe medical complications, prolonged length of stay, and unfavourable discharge increased incrementally with increasing levels of Frailty[44]. However, all these studies were not specifically dedicated to assess skull base and PCM surgery. Here we suggested, for the first time, the importance of assessing the patient general condition in order to improve the overall risk of postoperative complications. The ASA score and the modified Frailty index are significant predictors of post-operative severe non-neurological morbidity and overall severe morbidity and mortality, respectively, and remain convenient scores that can be achieved in daily clinical practice.

In parallel, we suggested that a low neurosurgical experience was associated with a higher risk of overall postoperative morbidity and mortality. The major role of the surgical experience could be related to the assessment of the risk of neurological and non-neurological complications from an experience-based multimodal analysis. The reduction of postoperative severe neurological impairment could be associated with higher skills of the neurosurgeon and the reduction of postoperative non-neurological morbidity is possibly related to the better selection of patients eligible for surgery.

In addition to the PCM's poor natural history $[8,10,13,42]$-as relentlessly progressive, with frequent fatal outcomes- and with the natural increased comorbidities score linked to the aging, one may argue that the surgical indication may be proposed early in the patient PCM history. Moreover, the advancement of surgical techniques, the outcomes of PCMs are no longer as pessimistic as has been reported previously $[3,6,20,21,26]$. The mortality rate has decreased greatly to $3 \%$; however, surgical morbidity remains high $[3,12,20,21,27]$. For selection of the ideal treatment modality in each case, understanding of the natural history and determination of preoperative predictors -such as comorbidity score- are mandatory[39]. A better understanding of the natural history of PCM in the elderly population may help to better wedged the surgical prognosis and the patient information, as comorbidities score appeared to be linked with poor outcomes.

Our results suggest incorporating general condition data into clinical and radiological data in order to improve the accuracy of predicting surgical risk for large and giant PCM.

\section{Generalizability}

This study captured the real-world practice of large and giant PCM surgery across a tertiary surgical skull base center. The present study controlled for patient-related and methodological biases by selecting a homogeneous population of large and giant petroclival meningioma in adults who all underwent surgical procedure by the same senior neurosurgeon. It represents a large single-center surgical experience. 
The present study: 1) could help identify pre-operatively patients with a significant risk of postoperative neurological and/or non-neurological morbidity; 2 ) highlights the need for a new integrated scoring system to assess pre-operatively the risk of the surgical procedure.

\section{Limitations}

These findings should be interpreted with caution, given the retrospective and monocentric design, the small numbers of patients, the rarity of the events analyzed, and the lack of an external validation set that limited the generalizability of the results. Since all patients in this study were adults, harbored a large and giant PCM surgically treated by the same senior neurosurgeon, and operated on using the same surgical approach, we thus cannot extend the results to other surgical techniques, to other location, and to patients with a recurrent large and giant PCM. In an attempt to identify predictors available before the surgery, we decided not to integrate the extent of surgical resection. In addition, for large and giant PCM, our attitude is to perform, when possible, a subtotal resection followed by Gamma-Knife radiosurgery, as previously described[6]. Finally, the median modified Frailty Index and Charlson comorbidity index was 0 , which suggests that patients who underwent surgery were already preselected by the neurosurgeon or by the referral physician.

Large and giant PCMs remain challenging surgical lesions requiring complex skull base approaches. The risk of postoperative severe neurological and non-neurological morbidity could be assessed preoperatively following clinical examination, brain MRI analysis and by scores assessing patients' comorbidities. In this study, we propose to add scores assessing the patient general condition in daily practice to improve the selection of patients eligible for surgery. This holistic approach for surgical risk could optimize the management of patients as well as selecting those who can benefit from a surgical resection. Collaborative international multicenter studies are required to confirm these results and allow their implementation in clinical routine.

\section{Declarations}

Funding: This research did not receive any specific grant from funding agencies in the public, commercial, or not-for-profit sectors.

Conflicts of interest/ Competing interests: None.

Availability of data and material: Anonymized data will be shared by request from any qualified investigator upon reasonable request.

Code availability: not applicable

Ethics approval: This study received required authorizations (IRB\#1: 2019/20) of the French College of Neurosurgery (IRB00011687).

Consent to participate: Informed consent was obtained from all patients. 
Consent for publication: Not applicable

\section{Authors' contributions:}

Alexandre Roux: Conception and design of the study, acquisition and analysis of data, Drafting a significant portion of the manuscript and figures.

Lucas Troude: Conception and design of the study, acquisition and analysis of data, Drafting a significant portion of the manuscript.

Guillaume Baucher: acquisition and analysis of data, Drafting a significant portion of the manuscript.

Florian Bernard: acquisition and analysis of data, Drafting a significant portion of the manuscript.

Johan Pallud: Conception and design of the study, Drafting a significant portion of the manuscript.

Pierre-Hugues Roche: Conception and design of the study, acquisition and analysis of data, Drafting a significant portion of the manuscript or figures.

\section{Acknowledgments}

Alexandre Roux would like to thank the Nuovo-Soldati Foundationfor Cancer Research and the Association Amicale des Anciens Internes en Médecine des Hôpitaux de Paris for their support.

\section{References}

1. Adachi K, Kawase T, Yoshida K, Yazaki T, Onozuka S (2009) ABC Surgical Risk Scale for skull base meningioma: a new scoring system for predicting the extent of tumor removal and neurological outcome. Clinical article. J Neurosurg 111:1053-1061. doi: 10.3171/2007.11.17446

2. Al-Mefty O, Fox JL, Smith RR (1988) Petrosal approach for petroclival meningiomas. Neurosurgery 22:510-517. doi: 10.1227/00006123-198803000-00010

3. Almefty R, Dunn IF, Pravdenkova S, Abolfotoh M, Al-Mefty O (2014) True petroclival meningiomas: results of surgical management. J Neurosurg 120:40-51. doi: 10.3171/2013.8.JNS13535

4. Beniwal M, Bhat DI, Rao N, Bhagavatula ID, Somanna S (2015) Surgical management of petroclival meningiomas: Factors affecting early post-operative outcome. Br J Neurosurg 29:559-564. doi: 10.3109/02688697.2015.1019422

5. Bernard F, Troude L, Isnard S, Lemée J-M, Terrier LM, François P, Velut S, Gay E, Fournier H-D, Roche P$\mathrm{H}$ (2019) Long term surgical results of 154 petroclival meningiomas: A retrospective multicenter study. Neurochirurgie 65:55-62. doi: 10.1016/j.neuchi.2019.02.001

6. Bernard F, Troude L, Isnard S, Lemée J-M, Terrier LM, François P, Velut S, Gay E, Fournier H-D, Roche P$\mathrm{H}$ (2019) Long term surgical results of 154 petroclival meningiomas: A retrospective multicenter study. Neurochirurgie 65:55-62. doi: 10.1016/j.neuchi.2019.02.001 
7. Bricolo AP, Turazzi S, Talacchi A, Cristofori L (1992) Microsurgical removal of petroclival meningiomas: a report of 33 patients. Neurosurgery 31:813-828; discussion 828. doi: 10.1227/00006123-199211000-00001

8. Castellano F, Ruggiero G (1953) Meningiomas of the posterior fossa. Acta Radiol Suppl 104:1-177

9. Charlson ME, Pompei P, Ales KL, MacKenzie CR (1987) A new method of classifying prognostic comorbidity in longitudinal studies: development and validation. J Chronic Dis 40:373-383. doi: 10.1016/0021-9681(87)90171-8

10. Cherington M, Schneck SA (1966) Clivus meningiomas. Neurology 16:86-92

11. Couldwell WT, Fukushima T, Giannotta SL, Weiss MH (1996) Petroclival meningiomas: surgical experience in 109 cases. J Neurosurg 84:20-28. doi: 10.3171/jns.1996.84.1.0020

12. Couldwell WT, Fukushima T, Giannotta SL, Weiss MH (1996) Petroclival meningiomas: surgical experience in 109 cases. J Neurosurg 84:20-28. doi: 10.3171/jns.1996.84.1.0020

13. Cushing HW, Eisenhardt L (1938) Meningiomas: Their Classification, Regional Behaviour, Life History and Surgical End Results. Springf. Charles $C$ Thomas

14. von Elm E, Altman DG, Egger M, Pocock SJ, Gøtzsche PC, Vandenbroucke JP, STROBE Initiative (2007) The Strengthening the Reporting of Observational Studies in Epidemiology (STROBE) statement: guidelines for reporting observational studies. Lancet Lond Engl 370:1453-1457. doi: 10.1016/S0140-6736(07)61602-X

15. Flexman AM, Charest-Morin R, Stobart L, Street J, Ryerson CJ (2016) Frailty and postoperative outcomes in patients undergoing surgery for degenerative spine disease. Spine J Off J North Am Spine Soc 16:1315-1323. doi: 10.1016/j.spinee.2016.06.017

16. Jiménez-Martínez E, Cuervo G, Hornero A, Ciercoles P, Gabarrós A, Cabellos C, Pelegrin I, GarcíaSomoza D, Adamuz J, Carratalà J, Pujol M (2019) Risk factors for surgical site infection after craniotomy: a prospective cohort study. Antimicrob Resist Infect Control 8:69. doi: 10.1186/s13756019-0525-3

17. Jung HW, Yoo H, Paek SH, Choi KS (2000) Long-term outcome and growth rate of subtotally resected petroclival meningiomas: experience with 38 cases. Neurosurgery 46:567-574; discussion 574-575. doi: 10.1097/00006123-200003000-00008

18. Khormi YH, Nataraj A (2020) Effect of length time to surgery on postoperative hospital length of stay among neurosurgical patients. Surg Neurol Int 11:144. doi: 10.25259/SNI_192_2020

19. Kim JW, Jung H-W, Kim YH, Park C-K, Chung H-T, Paek SH, Kim DG, Lee SH (2019) Petroclival meningiomas: long-term outcomes of multimodal treatments and management strategies based on 30 years of experience at a single institution. J Neurosurg 1-8. doi: 10.3171/2019.2.JNS182604

20. Li D, Tang J, Ren C, Wu Z, Zhang L-W, Zhang J-T (2016) Surgical management of medium and large petroclival meningiomas: a single institution's experience of 199 cases with long-term follow-up. Acta Neurochir (Wien) 158:409-425; discussion 425. doi: 10.1007/s00701-015-2671-6

21. Little KM, Friedman AH, Sampson JH, Wanibuchi M, Fukushima T (2005) Surgical management of petroclival meningiomas: defining resection goals based on risk of neurological morbidity and tumor 
recurrence rates in 137 patients. Neurosurgery 56:546-559; discussion 546-559

22. Mannion AF, Bianchi G, Mariaux F, Fekete TF, Reitmeir R, Moser B, Whitmore RG, Ratliff J, Haschtmann D (2020) Can the Charlson Comorbidity Index be used to predict the ASA grade in patients undergoing spine surgery? Eur Spine J Off Publ Eur Spine Soc Eur Spinal Deform Soc Eur Sect Cerv Spine Res Soc. doi: 10.1007/s00586-020-06595-1

23. Mayberg MR, Symon L (1986) Meningiomas of the clivus and apical petrous bone. Report of 35 cases. J Neurosurg 65:160-167. doi: 10.3171/jns.1986.65.2.0160

24. McGirt MJ, Bydon M, Archer KR, Devin CJ, Chotai S, Parker SL, Nian H, Harrell FE, Speroff T, Dittus RS, Philips SE, Shaffrey Cl, Foley KT, Asher AL (2017) An analysis from the Quality Outcomes Database, Part 1. Disability, quality of life, and pain outcomes following lumbar spine surgery: predicting likely individual patient outcomes for shared decision-making. J Neurosurg Spine 27:357-369. doi: 10.3171/2016.11.SPINE16526

25. Mitnitski AB, Mogilner AJ, Rockwood K (2001) Accumulation of deficits as a proxy measure of aging. ScientificWorldJournal 1:323-336. doi: 10.1100/tsw.2001.58

26. Nanda A, Javalkar V, Banerjee AD (2011) Petroclival meningiomas: study on outcomes, complications and recurrence rates. J Neurosurg 114:1268-1277. doi: 10.3171/2010.11.JNS10326

27. Natarajan SK, Sekhar LN, Schessel D, Morita A (2007) Petroclival meningiomas: multimodality treatment and outcomes at long-term follow-up. Neurosurgery 60:965-979; discussion 979-981. doi: 10.1227/01.NEU.0000255472.52882.D6

28. Park C-K, Jung H-W, Kim JE, Paek SH, Kim DG (2006) The selection of the optimal therapeutic strategy for petroclival meningiomas. Surg Neurol 66:160-165; discussion 165-166. doi: 10.1016/j.surneu.2005.12.024

29. Qiao L, Yu C, Zhang H, Zhang M, Qu Y, Ren M, Gu C, Wang H (2019) Clinical outcomes and survival analysis for petroclival meningioma patients receiving surgical resection: an analysis of 176 cases. Cancer Manag Res 11:5949-5959. doi: 10.2147/CMAR.S200932

30. Reponen E, Korja M, Niemi T, Silvasti-Lundell M, Hernesniemi J, Tuominen H (2015) Preoperative identification of neurosurgery patients with a high risk of in-hospital complications: a prospective cohort of 418 consecutive elective craniotomy patients. J Neurosurg 123:594-604. doi: 10.3171/2014.11.JNS141970

31. Roberti F, Sekhar LN, Kalavakonda C, Wright DC (2001) Posterior fossa meningiomas: surgical experience in 161 cases. Surg Neurol 56:8-20; discussion 20-21. doi: 10.1016/s00903019(01)00479-7

32. Roche P-H, Lubrano VF, Noudel R (2011) How I do it: epidural anterior petrosectomy. Acta Neurochir (Wien) 153:1161-1167. doi: 10.1007/s00701-011-1010-9

33. Saklad M (1941) GRADING OF PATIENTS FOR SURGICAL PROCEDURES. Anesthesiol J Am Soc Anesthesiol 2:281-284

34. Samii M, Ammirati M, Mahran A, Bini W, Sepehrnia A (1989) Surgery of petroclival meningiomas: report of 24 cases. Neurosurgery 24:12-17. doi: 10.1227/00006123-198901000-00003 
35. Schul DB, Wolf S, Krammer MJ, Landscheidt JF, Tomasino A, Lumenta CB (2012) Meningioma surgery in the elderly: outcome and validation of 2 proposed grading score systems. Neurosurgery 70:555-565. doi: 10.1227/NEU.0b013e318233a99a

36. Schuss P, Güresir Á, Schneider M, Velten M, Vatter H, Güresir E (2020) Factors influencing early postoperative complications following surgery for symptomatic spinal metastasis: a single-center series and multivariate analysis. Neurosurg Rev 43:211-216. doi: 10.1007/s10143-018-1032-3

37. Sebaaly A, Shedid D, Boubez G, Zairi F, Kanhonou M, Yuh S-J, Wang Z (2018) Surgical site infection in spinal metastasis: incidence and risk factors. Spine J Off J North Am Spine Soc 18:1382-1387. doi: 10.1016/j.spinee.2018.01.002

38. Sekhar LN, Jannetta PJ, Burkhart LE, Janosky JE (1990) Meningiomas involving the clivus: a six-year experience with 41 patients. Neurosurgery 27:764-781; discussion 781

39. Sekhar LN, Swamy NK, Jaiswal V, Rubinstein E, Hirsch WE, Wright DC (1994) Surgical excision of meningiomas involving the clivus: preoperative and intraoperative features as predictors of postoperative functional deterioration. J Neurosurg 81:860-868. doi: 10.3171/jns.1994.81.6.0860

40. Spetzler RF, Daspit CP, Pappas CT (1992) The combined supra- and infratentorial approach for lesions of the petrous and clival regions: experience with 46 cases. J Neurosurg 76:588-599. doi: 10.3171/jns.1992.76.4.0588

41. Tabouret E, Cauvin C, Fuentes S, Esterni B, Adetchessi T, Salem N, Madroszyk A, Gonçalves A, Casalonga F, Gravis $G$ (2015) Reassessment of scoring systems and prognostic factors for metastatic spinal cord compression. Spine J Off J North Am Spine Soc 15:944-950. doi: 10.1016/j.spinee.2013.06.036

42. Van Havenbergh T, Carvalho G, Tatagiba M, Plets C, Samii M (2003) Natural history of petroclival meningiomas. Neurosurgery 52:55-62; discussion 62-64

43. Wilson JRF, Badhiwala JH, Moghaddamjou A, Yee A, Wilson JR, Fehlings MG (2020) Frailty Is a Better Predictor than Age of Mortality and Perioperative Complications after Surgery for Degenerative Cervical Myelopathy: An Analysis of 41,369 Patients from the NSQIP Database 2010-2018. J Clin Med 9. doi: 10.3390/jcm9113491

44. Youngerman BE, Neugut Al, Yang J, Hershman DL, Wright JD, Bruce JN (2018) The modified frailty index and 30-day adverse events in oncologic neurosurgery. J Neurooncol 136:197-206. doi: $10.1007 / \mathrm{s} 11060-017-2644-0$

\section{Figures}


A The ASA score

\begin{tabular}{ll} 
Category & Physical Status \\
\hline ASA 1 & Normal healthy patient \\
ASA 2 & Patient with mild systemic disease \\
ASA 3 & Patient with severe systemic disease that is not a constant threat to life \\
ASA 4 & Patient with severe systemic disease that is a constant threat to life \\
ASA 5 & Moribund patient not expected to survive with or without surgery
\end{tabular}

B The modified Frailty index

\begin{tabular}{lc} 
Category & Score \\
\hline History of diabetes mellitus & 1 \\
History of congestive heart failure & 1 \\
History of hypertension requiring medication & 1 \\
History of either transient ischemic attack or cerebrovascular accident & 1 \\
Functional status 2 (not independent) & 1 \\
History of myocardial infarction & 1 \\
History of either peripheral vascular disease or rest pain & 1 \\
History of cerebrovascular accident with neurological deficit & 1 \\
History of chronic obstructive pulmonary disease or pneumonia & 1 \\
History of either percutaneous coronary intervention, prior cardiac surgery, or angina & 1 \\
History of impaired sensorium & 1
\end{tabular}

C The Charlson comorbidity index

\begin{tabular}{lc} 
Comorbidity & Score \\
\hline Prior myocardial infarction & 1 \\
Congestive heart failure & 1 \\
Peripheral vascular disease & 1 \\
Cerebrovascular disease & 1 \\
Dementia & 1 \\
Chronic pulmonary disease & 1 \\
Rheumatologic disease & 1 \\
Peptic ulcer disease & 1 \\
Mild liver disease & 1 \\
Diabetes & 1 \\
Cerebrovascular (hemiplegia) event & 2 \\
Moderate-to-severe renal disease & 2 \\
Diabetes with chronic complications & 2 \\
Cancer without metastases & 2 \\
Leukemia & 2 \\
Lymphoma & 2 \\
Moderate or severe liver disease & 2 \\
Metastatic solid tumor & 2 \\
Acquired immuno-deficiency syndrome (AIDS) & 3
\end{tabular}

\section{Figure 1}

Description of scores assessing patients' comorbidities A/ The American Society of Anaesthesiologists (ASA) score. B/ The modified Frailty index: functional status measured in the 30 days prior to surgery. The presence of each variable was scored as 1 point. The score ranges $0-11$, with a score 0 representing absence of frailty, while a score of 11 represents highest degree of frailty. C/ The Charlson Comorbidity 
Index: The score ranges $0-11$, with a score 0 representing absence of frailty, while a score of 37 represents highest degree of frailty.

\section{Supplementary Files}

This is a list of supplementary files associated with this preprint. Click to download.

- SupplementaryTable1.docx

- SupplementaryTable2.docx

- SupplementaryTable3.docx 